Anuario de

Derechos Humanos 2005 


\title{
El Informe de Chile ante el Comité de Derechos Económicos, Sociales y Culturales: el Papel del Derecho*
}

\author{
Domingo Lovera Parmo**
}

C hile se encontraba en mora respecto de sus obligaciones internacionales, y desde hace bastante tiempo. De acuerdo a los artículos 16 y 17 del Pacto Internacional sobre Derechos Económicos, Sociales y Culturales (en adelante "PIDESC" o "Pacto") ${ }^{1}$, los Estados parte -entre ellos Chile- "se comprometen a presentar ante el Comité de Derechos Económicos, Sociales y Culturales (en adelante "CDESC" o "Comité"), (...) informes sobre las medidas que hayan adoptado, y los progresos realizados, con el fin de asegurar el respeto de los derechos reconocidos" en él. Desde el retorno a la democracia, en 1990, y hasta julio de 2003, Chile no había presentado ningún informe al Consejo Económico y Social ${ }^{2}$. Tal situación fue revertida en 2003, con retardo claro está, fecha en la que el Estado de Chile presenta su informe relativo a la aplicación del PIDESC ${ }^{3}$.

El Informe del Estado chileno se divide en dos partes. La primera de ellas, con una introducción, se encarga de las disposiciones generales del Pacto, al tiempo que detalla el estado de la situación económica, política y social por la que Chile ha atravesado desde 1990. La segunda parte, en cambio, se encarga de detallar, artículo por artículo, el estado de avance de cada uno de los derechos del mismo. Examinar la segunda parte -de más de 200 páginas- excede, con mucho, el objetivo del presente comentario. Por esta razón, he preferido centrarme en la primera sección del informe y, dentro de ella, sobre una ausencia que me llama particularmente la atención: el sistema de protección judicial de los Derechos Económicos, Sociales y Culturales (en adelante "DESC").

En efecto, la primera de estas partes se encarga de contextualizar -no podría entenderse de otra forma- el estado económico y social de Chile desde 1990 a 2003, período que cubre el informe. En esa línea, presta especial atención (a) al crecimiento económico de Chile, (b) a las diferentes crisis del mismo orden que se han debido sortear, (c) a los cambios en nuestra institucionalidad y (d) a las políticas públicas implementadas por el Estado; sin embargo, omite referencia alguna al sistema judicial de protección (y exigibilidad) de los DESC, en circunstancias que el propio Pacto establece que los Estados tienen el deber de "garantizar el ejercicio de los derechos que en él se enuncian, sin discriminación" ${ }^{4}$. De hecho, el estado de nuestra jurisprudencia sobre DESC, ausente en el informe, es lo que también llamó la atención
* Las observaciones al informe de Chile del Comité de Derechos Económicos, Sociales y Culturales, se encuentran en la Sección Documentos de Interés de este Anuario.

** Profesor de Derecho, Abogado del Programa de Acciones de Interés Público y Derechos Humanos, Universidad Diego Portales.

Agradezco los comentarios de Nicolás Espejo, en particular en lo relativo al sistema internacional de protección de los Derechos Humanos.

Ver las notas de este texto a partir de la página 173.

Este comentario, junto con el documento principal a que se refiere, están disponibles en formato digital en www.anuariocdh.uchile.cl 
del Comité en las observaciones que, sobre este informe, realizó 5 . Señala el Comité que "está preocupado porque algunos derechos económicos, sociales y culturales (...) no son considerados justiciables en el Estado Parte [Chile]. En este sentido, el Comité hace notar la escasez de casos judiciales en los cuales se hayan invocado los derechos del Pacto ante y para su aplicación, en los tribunales" ${ }^{\prime \prime}$.

Y no se trata de un tema menor, pues ese sistema -permítanme que lo denomine así- es el que presenta en Chile graves deficiencias. Esas deficiencias, como se verá, se detectan tanto desde el punto de vista del establecimiento de estos derechos en la Constitución -y las garantías para su tutela-como desde el punto de vista de la respuesta que nuestras cortes entregan a casos en que se invocan los mismos.

En lo que sigue entregaré, brevemente, (1) una reseña de la forma en que se consagra el recurso judicial que se encarga de tutelar derechos fundamentales ${ }^{7}$ : la acción de protección. Luego, (2) daré cuenta de algún pronunciamiento de nuestros tribunales al respecto, para, hacia el final, (3) dar algunas conclusiones relacionadas con la ausencia detectada.

(1) La Constitución Política de la República de Chile (en adelante "Constitución"), dedica su Capítulo III a los Derechos y Deberes Constitucionales de las personas. Junto con establecer un catálogo de derechos, no taxativo - de conformidad al artículo $5^{\circ}$ de la Constitución-, estatuye dos acciones constitucionales encargadas de entregar tutela judicial a las personas: la acción de protección y el recurso de amparo (habeas corpus).

La primera de ellas, que para estos efectos interesa, opera en el caso en que una persona o varias se vean amenazadas, perturbadas o privadas del ejercicio legítimo de sus derechos, sea a través de un acto u omisión, arbitrario o ilegal ${ }^{8}$, imputable al Estado o a un particular ${ }^{9}$. Nada nuevo hasta acá, entonces. Los requisitos para que proceda esta acción son: (a) que se trate de un acto u omisión; (b) arbitrario o ilegal (o arbitrario e ilegal); (c) que cause amenaza, perturbación o privación; (d) del ejercicio legítimo de los derechos a las personas; (e) siendo ese acto $u$ omisión imputable al Estado o a algún particular ${ }^{10}$.

Ahora bien, ocurre que la Constitución, una vez que consagra la acción, se encarga de reducir su efecto de tutela pues excluye algunos derechos de su halo protector. Aquellos derechos que quedan bajo su tutela, para el caso de que sean perturbados o amenazados o que haya habido privación de los mismos, son los de corte libertario o individual (libertad de expresión, propiedad privada, vida privada, libertades económicas y de conciencia, entre otros). Son excluidos, en cambio, los de contenido económico, social y cultural (derecho al trabajo, a la salud y educación, típicamente) ${ }^{11}$.

¿Qué explica esta distinción en nuestra Constitución? Tres, me parece, son los factores que dan respuesta a esta pregunta. Primero, el hecho 
de que nuestra Constitución concibe a los DESC de conformidad a las tesis más tradicionales, aquellas que sostienen que poseen una diferencia estructural con los de corte libertario toda vez que, a diferencia de éstos, los primeros para su exigibilidad requieren la actividad prestacional del Estado (y no solo su abstención) ${ }^{12}$. Segundo, como los DESC tienen que ver con la elaboración e implementación de políticas públicas, los miembros de la Comisión de Estudios para la Nueva Constitución de seguro no vieron con muy buenos ojos abrir la posibilidad para que la ciudadanía, vía Poder Judicial, fuera titular de acciones que le permitirían controlar al Estado en el diseño de sus directrices sociales. Y, tercero, el contexto en que se elaboró nuestra Constitución. Insisto, y muy vinculado con lo anterior, quienes detentaban entonces de facto el poder, no estaban interesados en una ciudadanía controladora del desempeño del Gobierno, menos en el diseño de políticas públicas. En verdad, podría decirse, no estaban interesados en forma alguna de ciudadanía.

(2) Señalé que me interesaba remarcar la ausencia de toda mención al sistema judicial de protección de los derechos humanos en Chile, no por capricho - propio de la profesión que ejerzo, por lo demássino porque creo que es en esa rama del poder en donde se han verificado varios pronunciamientos relevantes a la hora de medir la exigibilidad de los DESC. Permítanme pasar rápida revista a algunos de ellos, para luego elaborar algunas conclusiones.

En materia de salud, unos de los casos más interesantes que se plantearon a tribunales vía recurso de protección, fueron las solicitudes de medicamentos (tri-terapias) de personas portadoras de $\mathrm{VIH}^{13}$. El año 2000, y luego de varios intentos frustrados, la Corte de Apelaciones falla sobre uno de los recursos, rechazándolo al disponer que "no puede estimarse [como conductas que ponen en peligro la vida humana] las omisiones que se atribuyen a los servicios de salud y al MINSAL, puesto que el peligro a la vida de los recurrentes deriva de la enfermedad de que, lamentablemente, padecen pero no de las autoridades sanitarias ${ }^{\prime 14}$. Al año siguiente, uno de los recursos fue acogido por la Corte de Apelaciones de Santiago, señalando que "el derecho a la vida es un derecho de carácter absoluto y al margen de toda negociación patrimonial"15 ${ }^{\prime 1}$. La Corte estimó que establecer un orden de prelación para el acceso a las triterapias, que dependía en última instancia de consideraciones económicas, significaba una discriminación arbitraria respecto a personas que estaban en una misma situación. La Corte Suprema, empero, revocó el fallo señalando -como es común-que se trata de "un problema de salud pública, cuyas políticas deben ser definidas por las autoridades públicas pertinentes del ministerio indicado, que constituyen el personal idóneo para la fijación de las normas de acceso a las prestaciones que, como en el caso de autos, se pretenden, habida cuenta que en su otorgamiento han de tenerse en cuenta variados parámetros, entre otros, como resulta evidente, el relativo a los costos que ellos involucren y los fondos de que se dispone 
para ello ${ }^{\prime 16}$. Como se conoce, este tipo de argumentaciones es el que se tuvo en mente al momento de establecer la limitación al recurso de protección, como acción de tutela de los DESC ${ }^{17}$.

En el caso de la "Asociación chilena de defensa para personas con enfermedades catastróficas y terminales, con el Ministerio de Salud", un grupo de personas, portadoras de estas enfermedades, requirió ante la Corte de Apelaciones de Santiago la entrega de asistencia médica gratuita, por no tener lo medios necesarios para costearlos. El Estado, evacuando el informe en este recurso de protección, respondió que "la actividad del Estado en materia de salud queda dentro de su función de gobierno y administración, [por lo cual], la fijación de los planes, programas y políticas, queda dentro de la función de gobierno (sic), y el otorgamiento de prestaciones de salud es propia de la función de administración del ejecutivo, por intermedio del ministerio respetivo". La Corte rechazó el recurso como acción colectiva, pero hizo lugar a la petición del recurrente, ordenando al Estado a entregar la asistencia requerida ${ }^{18}$. Con todo, queda de manifiesto el tipo de alegaciones que presenta el Estado a la hora de ser interpelado en tribunales ${ }^{19}$.

En materia de educación, por su parte, el problema con que se han encontrado quienes reclaman derecho a ella, es que las cortes suelen distinguir el tipo de colegios en contra de los cuales se reclama. Si es del caso que estamos en presencia de colegios municipalizados o subvencionados, las cortes suelen ejercer sus facultades para ordenar el reestablecimiento del derecho. El problema se presenta cuando el colegio es privado, momento en el que la autonomía de la voluntad, al parecer, se erige como una barrera infranqueable para los demás derechos (como la igualdad). Así, en el caso de Natalia Vergara -el caso de una niña de 6 años, cuya matrícula fue cancelada por comer goma de mascar en clases y retirar las hojas de la libreta escolar en que se daba cuenta de ese hecho a sus padres ${ }^{20}$ - la Corte de Apelaciones acogió el recurso señalando que: a) el reglamento prevé la cancelación de matrícula como una sanción, lo que es lícito; b) para su aplicación deben verificarse ciertos requisitos; c) la primera sanción que se aplica a un alumno no puede ser la cancelación de matrícula cuando el mismo reglamento contempla otras de menor jerarquía que, en orden gradual, deben ir aplicándose; d) cuando un colegio aplica la cancelación de matrícula como primera medida, obviando los requisitos exigidos por el reglamento para su procedencia, incurre en un acto arbitrario e ilegal que, además, "[i]mporta un atentado contra lo que resulta ser la base indispensable para alcanzar una educación plena, la continuidad, el hecho de que se le impida, por razones no justificadas, seguir sus estudios en un determinado establecimiento educacional" ${ }^{21}$. La Corte Suprema, conociendo de la apelación del fallo, resolvió revocar la sentencia señalando que el contrato de prestación de servicios educacionales es eso, un contrato, y que, por lo tanto, "la libertad de un ciudadano de escoger determinado establecimiento de enseñanza para sus hijos, no significa que dicho establecimiento está en la obligación de recibirlos ni tampoco, mantenerlo en él, a menos que se pacte lo contrario" ${ }^{22}$. 
Esa autonomía de la voluntad, elevada por la Corte Suprema a la categoría de derecho absoluto, sería, luego, relativizada en el caso "Palma, Arturo con Isapre Colmena Golden Cross S.A.". Se trataba del caso de una persona que conjugaba dos hipótesis de discriminación: era una persona mayor de 60 años y ciego. Arturo Palma, debido a las alzas excesivas del plan de salud de su isapre, decidió afiliarse a una nueva institución de salud previsional. Una vez que pasó por todos los trámites de rigor -entre ellos, como señaló la Corte, "invasivos exámenes de salud"- la isapre decidió rechazar su afiliación sin expresar las razones para tal decisión. Al resolver sobre estos hechos ${ }^{23}$, la Corte de Apelaciones -en fallo confirmado por la Corte Suprema- señaló que la autonomía de la voluntad no puede ejercerse con absoluta discrecionalidad por parte de las isapres, pues los derechos fundamentales actúan como un límite ${ }^{24}$.

Finalmente, y para terminar esta rápida revisión, cabe hacer referencia a un importante pronunciamiento del Tribunal Constitucional, a propósito del proyecto de ley de Jornada Escolar Completa ${ }^{25}$. Señaló el Tribunal Constitucional, "[q]ue el deber del Estado de otorgar la referida enseñanza gratuita ya explicado ha de ser cumplido por iniciativa propia y con diligencia especial, siendo insostenible argumentar, desde el ángulo de la interpretación de buena fe, finalista y razonable de la Constitución que, por no haber sido contempladas acciones y recursos jurisdiccionales de jerarquía constitucional para compeler a los órganos públicos competentes a cumplir ese trascendental cometido, se hallen en situación de eludirlo, o satisfacerlo discrecionalmente. Nunca cabe olvidar lo mandado en el artículo $6^{\circ}$ del Código Político, base institucional que exige de las autoridades públicas, sin salvedad ni omisión, cumplir lo ordenado en él" ${ }^{\prime 26}$.

Es decir, la sentencia en comento asume que (a) la iniciativa en la satisfacción de los DESC corresponde al Estado; (b) que el hecho de estar fuera de la tutela de la acción de protección, no es un argumento que pueda utilizarse para eludir el cumplimiento de su contenido; (c) todo ello, por el carácter finalista de la Constitución que pone el acento en la persona, en la satisfacción del interés público y la generación de condiciones sociales que permitan el desarrollo tanto material como espiritual. Pese a lo importante de esta sentencia, las interpretaciones del Tribunal Constitucional, en Chile, nunca han sido tomadas en cuenta por el Poder Judicial.

(3) He señalado que pretendía, al ilustrar los puntos anteriores, y siempre situado en la parte primera del informe chileno al Consejo Económico y Social de las Naciones Unidas, Ilamar la atención sobre la escasa alusión de ese informe al sistema de derechos que rige en nuestro país. En el informe se señala que "Chile destaca en el ámbito internacional por las reformas institucionales que ha venido desarrollando, desde la década de los noventa en las áreas de previsión, educación y salud ${ }^{\prime 27}$. Presentada esa declaración por parte del Estado chileno, se omite, sin embargo, cualquier tipo de referencia al sistema jurídico de protección de los DESC. 
Como he señalado, una Constitución como la chilena asume que los DESC son un tipo de derechos que requieren -en esa distinción tradicional que se hace- un rol activo del Estado. Por esa razón, entre otras, estos derechos quedan al margen de la protección jurídica que brinda el recurso de protección. ¿Es ésta de una discusión que interesa solo a académicos del derecho? Las reformas de las cuales se jactan nuestras autoridades han configurado, en los hechos, una suerte de doble régimen en que, quienes poseen recursos económicos, se sitúan al amparo del sistema privado de salud y educación. Quienes no los poseen, en cambio, se colocan bajo el alero estatal. No se trata de una distinción irrelevante; quienes se ubican en el primer grupo gozan de mayores y mejores niveles de cobertura de sus derechos. Aunque el sistema internacional de protección de los DESC prohibe que las personas gocen en mayor o menor medida de los derechos, dependiendo de los recursos económicos con que cuentan, en Chile, ello es asi ${ }^{28}$.

¿Cuál es la respuesta de nuestro sistema jurídico y judicial a ese tipo de desigualdades que se verifican en la práctica? El Estado chileno ha preferido omitir una mirada a esta problemática, quizás porque considera que en estos asuntos el papel del derecho, y en particular, el papel de los derechos fundamentales, es menor. En efecto, y así lo ha entendido parte de nuestra jurisprudencia, cada vez que una política pública llega a conocimiento de nuestros tribunales, las Cortes, amparadas en una versión débil de lo que una separación de poderes es, han rechazado pronunciarse sobre estas materias ${ }^{29}$. Sostienen, en general, que se trata de regulaciones que solo al "Gobierno Central" corresponde diseñar e implementar y que, inmiscuirse en ellas, sería equivalente a obviar la separación de poderes que nuestra Constitución estatuye en su artículo $7^{\circ}$.

El desarrollo por parte de nuestros tribunales de estándares de derechos fundamentales, como ocurrió en la sentencia del caso "Palma, Arturo con Isapre Colmena Golden Cross S.A.", es escaso. Y aun cuando nuestros tribunales fueran prolíferos en tal desarrollo, la ausencia de un sistema de precedentes impide que esos estándares sean invocados y (otra vez) desarrollados en nuevos casos.

Mientras la Constitución no entrega resguardo a los DESC por medio de la acción idónea para ello -el recurso de protección- nuestras Cortes no han hecho mucho más. Las sentencias que recogen y desarrollan estándares de Derechos Humanos son las menos, y ni hablar de aquellas que desarrollan estándares de derecho internaciona $\left.\right|^{30}$. Pero el Estado chileno ha preferido colocar la atención en las reformas institucionales, dejando de lado el rol del derecho, del sistema jurídico y de nuestros tribunales. 


\section{Notas}

1 El PIDESC fue adoptado por la Asamblea General de las Naciones Unidas el 19 de diciembre de 1966. Fue suscrito por Chile el 16 de septiembre de 1969 y ratificado el 10 de febrero de 1972. Sin embargo, solo se encuentra vigente en nuestro país desde el 27 de mayo de 1989, fecha en que se publica en el Diario Oficial (Decreto №326, Ministerio de Relaciones Exteriores).

2 Véase Informe Anual sobre Derechos Humanos en Chile 2003 (hechos de 2002), Universidad Diego Portales, Santiago, 2003, p. 382.

3 Aplicación del Pacto Internacional de Derechos Económicos, Sociales y Culturales, Terceros informes periódicos que deben presentar los Estados Partes de conformidad a los artículos 16 y 17 del Pacto, Consejo Económico y Social, Naciones Unidas, 10 de julio de 2003.

4 Artículo 2.2 del PIDESC. Como lo señaló la Corte Interamericana de Derechos Humanos, en el caso Velásquez Rodríguez, el deber de garantía "implica el deber de los Estados Partes de organizar todo el aparato gubernamental $y$, en general, todas las estructuras a través de las cuales se manifiesta el ejercicio del poder público, de manera tal que sean capaces de asegurar jurídicamente el libre y pleno ejercicio de los derechos humanos. Como consecuencia de esta obligación, los Estados deben prevenir, investigar y sancionar toda violación de los derechos reconocidos por la Convención y procurar, además, el restablecimiento, si es posible, del derecho conculcado y, en su caso, la reparación de los daños producidos por la violación de los derechos humanos. Véase, Caso Velásquez Rodríguez, Corte Interamericana de Derechos Humanos, 29 de julio de 1988.

5 Consideration of Reports Submitted by States Parties, Under Articles 16 and 17 of the Covenant, Economic and Social Council, United Nations, 26 November 2004.

6 Párrafo 12, Consideration of Reports Submitted (cit.). El Comentario General número 1, ya había indicado que la obligación de los Estados, al presentar sus informes, era la de mostrar "la actual situación de respeto a cada uno de los derechos (...) si están, o no están, siendo disfrutados por todos los individuos (..) objetivo que no se alcanza sólo con la agregación de estadísticas o estimaciones". Párrafo 3, Reporting by States Parties, General Comment 1, Economic and Social Council, United Nations, 24 February 1989 (traducción del autor).

7 Utilizaré indistintamente, aunque consciente de su diferencia conceptual, los términos derechos humanos y derechos fundamentales.

8 Como es de suponer, se trata de requisitos que pueden confluir en una misma hipótesis de vulneración de derechos. Es decir, en un mismo recurso puede reclamarse un acción y una omisión y, una y otra, pueden ser, al mismo tiempo, arbitrarias e ilegales.

9 El tema acá no es pacífico. Si bien es cierto que los derechos fundamentales, en su génesis, nacen como prerrogativas de los particulares frente al poder del Estado, el desarrollo del constitucionalismo extendió su poder normativo a los particulares. Es decir, estos derechos ya no son solo oponibles al Estado (efecto vertical), sino también a los particulares (efecto horizontal o -en la versión alemana que desarrolló esta tesis- Drittwirkung). Nuestra constitución recoge este segundo efecto en su artículo $6^{\circ}$; la redacción de la acción de protección deja abierta la puerta para que ella opere entre particulares y nuestra jurisprudencia lo ha aceptado. Existen, con todo, varios niveles en que opera este efecto. Véase LOVERA, Domingo, La Respuesta Razonable: el estándar de los Derechos Fundamentales, en Revista Gaceta Jurídica de los Tribunales № 285 (marzo), Editorial LexisNexis Chile, Santiago, pp. 46-47.

${ }^{10} \mathrm{~A}$ los requisitos que exige la Constitución deben sumarse los demás que, a través de diversos Autos Acordados, ha sumado la Corte Suprema. Esos Autos Acordados poseen dudosa constitucionalidad y su efecto, en la protección de los derechos humanos, ha sido pernicioso. Véase Informe Anual sobre Derechos Humanos en Chile 2004 (hechos de 2003), Universidad Diego Portales, Santiago, 2004, pp. 28-38.

${ }^{11}$ No debe olvidarse que el Estado de Chile aún no ratifica el Protocolo Adicional a la Convención Americana sobre Derechos Humanos en materia de Derechos Económicos, Sociales y Culturales de 1998, con todas las implicancias que ello trae para la exigibilidad. Véase Informe Anual sobre Derechos Humanos en Chile 2003 (cit.), p. 380.

12 La Declaración y Programa de Acción de Viena, estipula que "[t]odos los derechos humanos son universales, indivisibles e interdependientes y están relacionados entre sí", debiendo tratarse en "forma conjunta". Sobre la obligación de los Estados de dotar a sus ciudadanos 
de un recurso eficaz en la defensa de sus derechos humanos, véase The nature of States Parties obligations (Art.2, par.1) General Comment 3, Economic and Social Council, United Nations, 14 December 1990. Sobre la fundamentación teórica de la exigibilidad de los DESC, véase, ABRAMOVICH, Víctor y COURTIS, Christian, Los derechos sociales como derechos exigibles, Editorial Trotta, Madrid, 2002 (en particular, Capítulo 1).

${ }^{13} \mathrm{Si}$ bien es cierto que el derecho a la salud no se encuentra tutelado por la acción de protección, en estos casos, lo que se hizo, fue presentar las acciones reclamando la violación del derecho a la vida, el cual no solo acarrea obligaciones negativas para el Estado (no matar a sus ciudadanos) sino también positivas (prestacionales, si se les quiere llamar así). Sobre esta interpretación, véase, ZÚÑIGA, Alejandra, El Interés Público del Derecho a la Vida, en GONZÁLEZ, Felipe (ed.), Litigio y Políticas Públicas en Derechos Humanos, Cuadernos de Análisis Jurídico, Serie de Publicaciones Especiales Nº14, Universidad Diego Portales, Santiago, 2002, en especial, pp.100-106.

${ }^{14}$ Corte de Apelaciones de Santiago, sentencia de 6 de noviembre de 2000.

15 Corte de Apelaciones de Santiago, sentencia de 28 de agosto de 2001.

16 Corte Suprema, 9 de octubre de 2001.

17 No es del caso de este comentario, pero alguna estrategia sugiere la posibilidad de examinar las políticas públicas a la luz de los derechos que sí están tutelados. ¿Qué ocurre si una política pública es discriminatoria? ¿Deberán los tribunales abstenerse de conocer por el solo hecho de ser una política pública? Algunas conclusiones al respecto en F. H. Zwaan - de Vries v. The Netherlands, Communication No. 182/1984 (9 April 1987), U. N. Doc. Supp. No.40 (A/42/40) at 160 (1987).

18 Véase Informe Anual sobre Derechos Humanos en Chile 2003 (cit.), p. 385.

${ }^{19}$ Esta estrategia fue seguida por el Estado chileno, también, en los casos de personas portadoras de VIH. La Corte Suprema, revocando una sentencia que otorgaba a estas personas derecho a la tri-terapia, señaló que se trata de "un problema de salud pública, cuyas políticas deben ser definidas por las autoridades públicas pertinentes del ministerio indicado, que constituyen el personal idóneo para la fijación de las normas de acceso a las prestaciones que, como en el caso de autos, se pretenden, habida cuenta que en su otorgamiento han de tenerse en cuenta variados parámetros, entre otros, como resulta evidente, el relativo a los costos que ellos involucren y los fondos de que se dispone para ello". Sentencia Corte Suprema, 9 de octubre de 2001. Para revisar los antecedentes sobre los casos de personas portadores del VIH/SIDA: http://www.derechoshumanosudp.cl/ res_clin/derch.asp.

20 Todos los antecedentes del caso en: http://www.derechoshumanosudp.cl/res_clin/ casnat.asp.

${ }^{21}$ Corte de Apelaciones de Santiago, 17 de febrero de 2003.

22 Corte Suprema, 8 de abril de 2003.

${ }^{23}$ Los demás antecedentes en: http://www.derechoshumanosudp.cl/res_clin/dicrim.asp.

${ }^{24}$ Corte de Apelaciones de Santiago, 4 de septiembre de 2003. Para comentario de esta sentencia, en extenso, véase, LOVERA, Domingo, La Respuesta Razonable (cit.).

25 En esta última, una de las normas que mayor debate ha generado, es la incorporación de un nuevo requisito para los colegios que deseen optar al financiamiento estatal: los colegios deberán incorporar una cuota de 15\% de alumnos vulnerables. Esta regla, como se sabe, fue objeto de un requerimiento ante el TC (junto a otras, entre ellas, la que establecía un sistema de resguardo de derechos para los alumnos cuyos padres no pagaran las matrículas. Ésta, a diferencia de la referente a las cuotas, no pasó el control).

${ }^{26}$ Considerando 23ㅜ, Sentencia TC, Rol 410-2004, 14 de junio de 2004 (el destacado es mío). A pesar que la sentencia asume que el Estado no posee discrecionalidad para satisfacer estos derechos del modo que le parezca (sin sujeción a estándar alguno de control), un sistema jurídico como el chileno asume la existencia de un Tribunal Constitucional encargado de la vigilancia de la Constitución. El resto de los tribunales, en este tipo de sistemas (el dual) se encargan de aplicar la ley. Las relaciones entre Tribunal Constitucional y demás tribunales, o no existen, o son escasas.

27 Aplicación del Pacto Internacional (cit.), p.5.

${ }^{28}$ El artículo 2.2 del PIDESC, establece que es deber de los Estados "garantizar el ejercicio de los derechos sin discriminaciones". En concordancia con esto, el CDESC, ha señalado 
que los Estados tienen el deber de "velar por una distribución equitativa de todas las instalaciones, bienes y servicios de salud". Citado en Informe Anual sobre Derechos Humanos en Chile 2003 (hechos de 2002), p. 399.

${ }^{29}$ La separación de poderes puede entenderse en dos versiones. (1) Una primera respuesta sería entender que la separación de poderes supone que cada uno de los diferentes departamentos estatales posee atribuciones que ejerce con total autonomía, esto es, sin que ninguno de los otros departamentos pueda inmiscuirse ni pronunciarse sobre la forma en que uno resuelve sus asuntos. (2) Una segunda respuesta posible, por su parte, dirá que la separación de poderes no significa que cada uno de los departamentos estatales se muevan dentro de sus atribuciones sin que nadie pueda fiscalizarlos, en cambio, que cada uno de ellos posee atribuciones que ejerce privativamente, pero que ello no supone que ningún otro órgano fiscalizará esas decisiones a objeto de evitar discrecionalidad (fuerte) en ese ejercicio. Esta segunda idea, planteada por Madison en 1788, supone que un Estado de Derecho debe incorporar distintas instancias encargadas de balancear el poder que concentra el Estado, con el objeto de evitar que este se acumule en un solo órgano.

${ }^{30}$ En este sentido hay situaciones, incluso, mucho más curiosas. En el caso de la "Obra Prat", en donde descendientes del Capitán de Fragata solicitaban a la Corte de Apelaciones de Santiago que prohibiera la puesta en escena de esa obra, el tribunal rechazó la petición, entre otras razones, echando mano a los estándares internacionales en materia de libertad de expresión. La Corte Suprema, a pesar de ratificar la sentencia que rechazaba la censura de la obra, eliminó (sin que existan razones que lo expliquen) toda referencia al sistema internacional de Derechos Humanos. Los detalles de este caso, así como las sentencias del mismo, en: http://www.derechoshumanosudp.cl/res_clin/intent.asp. 